\title{
Derivation of Kinetic Equations for Free-Radical Nonbranched-Chain Processes of Hydrocarbon and Hydrogen Oxidation
}

\author{
Michael M. Silaev \\ Chemistry Faculty, Lomonosov Moscow State University, Vorobievy Gory, Moscow 119991, Russia \\ Correspondence should be addressed to Michael M. Silaev: mmsilaev@gmail.com
}

Copyright () 2022 Made Michael M. Silaev. This is an open access article distributed under the Creative Commons Attribution License, which permits unrestricted use, distribution, and reproduction in any medium, provided the original work is properly cited.

\begin{abstract}
The derivation of kinetic equations for the oxidation processes by the free-radical nonbranched-chain mechanism is shown. This derivation is based on the proposed reaction scheme for the initiated addition of free radicals to the multiple bond of the molecular oxygen includes the addition reaction of the peroxyl free radical to the oxygen molecule to form the tetraoxyl free radical. This reaction competes with chain propagation reactions through a reactive free radical. The chain evolution stage in this scheme involves a few of free radicals, one of which (tetraoxyl) is relatively low-reactive and inhibits the chain process by shortening of the kinetic chain length. The rate equations (containing one to three parameters to be determined directly) are deduced using the quasi-steady-state treatment. The kinetic description with use the obtained rate equations is applied to the $\gamma$-induced nonbranched-chain processes of the free-radical oxidation of liquid $o$-xylene at $373 \mathrm{~K}$ and hydrogen dissolved in water containing different amounts of dioxygen at $296 \mathrm{~K}$. The ratios of rate constants of competing reactions and rate constants of addition reactions to the molecular oxygen are defined. In these processes the oxygen with the increase of its concentration begins to act as an oxidation autoinhibitor (or an antioxidant), and the rate of peroxide formation as a function of the dissolved oxygen concentration has a maximum. It is shown that a maximum in these curves arises from the competition between hydrocarbon (or hydrogen) molecules and dioxygen for reacting with the emerging peroxyl 1:1 adduct radical. From the energetic standpoint possible nonchain pathways of the free-radical oxidation of hydrogen and the routes of ozone decay via the reaction with the hydroxyl free radical in the upper atmosphere (including the addition yielding the hydrotetraoxyl free radical, which can be an intermediate in the sequence of conversions of biologically hazardous UV radiation energy) were examined. The energetics of the key radical-molecule gas-phase reactions is considered.
\end{abstract}

KEYWORDS - Low-Reactive Radical, Autoinhibitor, Competition, Thermochemical Data, Hydrogen, Energy.

\section{INTRODUCTION}

The kinetics of inhibition for nonbranched-chain processes of saturated free-radical addition to the $\mathrm{C}=\mathrm{C}$ and $\mathrm{C}=\mathrm{O}$ double bonds of alkene and formaldehyde molecules, respectively, by low-reactive free radicals that can experience delocalization of the unpaired $p$-electron was first considered in [1]. In these processes a low-reactive free radical is formed in the reaction competing with chain propagation reactions through a reactive free radical. In the present work the kinetics of inhibition by low-reactive tetraoxyl free radicals is considered for nonbranched-chain processes of the addition of a free radical or an atom to one of the two multiply bonded atoms of the oxygen molecule yielding a peroxyl free radical and thus initiating oxidation, which is the basic process of chemical evolution. The peroxyl free radical then abstracts the most labile atom from a molecule of the compound being oxidized or decomposes to turn into a molecule of an oxidation product. The only reaction that can compete with these two reactions at the chain evolution stage is the addition of the peroxyl radical to the oxygen molecule (provided that the oxygen concentration is sufficiently high). This reaction yields the secondary tetraoxyl 1:2 adduct radical, which is the heaviest and the largest among the reactants. It is less reactive than the primary peroxyl 1:1 adduct radical and, as a consequence, does not participate in further chain propagation. At moderate temperatures, the reaction proceeds via a nonbranched-chain mechanism. The aim of this study was the mathematical simulation of oxidation process autoinhibited by oxygen, when the dependence of the peroxide formation rate on the dissolved oxygen concentration has a maximum, and show the derivation of kinetic oxidation equations. The simulation was based on experimental data obtained for $\gamma$-radiation-induced addition reaction of hydrocarbon free radical $\mathrm{R}^{\cdot}$ (or hydrogen atom) to the molecular oxygen for which the initiation rate $V_{1}$ is known (taking into account that $V=G P$ and $V_{1}=\varepsilon G\left(\mathrm{R}^{\circ}\right) P$, where $P$ is the dose rate, $\varepsilon$ is the electron fraction of the solvent RH in the binary system [2], and $G\left(\mathrm{R}^{*}\right)$ is the initial yield of the chain-carrier free radical $\mathrm{R}^{\cdot}$ - initiation yield $[3,4]$ ).

Based on the reaction scheme suggested for the kinetic 
description of the addition process to oxygen, the kinetic equations with one to three parameters to be determined directly were derived. Reducing the number of unknown parameters in a kinetic equation will allow one to decrease the narrowness of the correlation of these parameters and to avoid a sharp buildup of the statistical error in the nonlinear estimation of these parameters in the case of a limited number of experimental data points. The rate constant of the addition to oxygen, estimated as a kinetic parameter, can be compared to its reference value if the latter is known. This provides a clear criterion to validate the mathematical description against experimental data.

\section{ADDITION OF HYDROCARBON FREE RADICALS}

Usually, the convex curve of the hydrocarbon autooxidation rate as a function of the partial pressure of molecular oxygen ascends up to some limit and then flattens out [5]. When this is the case, the oxidation kinetics is satisfactorily describable in terms of the conventional reaction scheme [5-10], which involves two types of free radicals. These are the hydrocarbon radical $\mathrm{R}^{\circ}$ (addend radical) and the addition product $\mathrm{RO}_{2}^{\circ}(1: 1$ adduct radical). However, the existing mechanisms are inapplicable to the cases in which the rate of initiated oxidation as a function of the oxygen concentration has a maximum (Figs. 1 and 2) [11, 12]. Such dependences can be described in terms of the competition kinetics of free-radical chain addition, whose reaction scheme involves not only the above two types of free radicals, but also the $\mathrm{RO}_{4}^{\cdot}$ radical (1:2 adduct) inhibiting the chain process $[13,14]$.

\section{Scheme 1}

Nonbranched-chain oxidation of hydrocarbons ${ }^{1}$

Chain initiation

1. $\mathrm{I} \stackrel{2 k_{1}}{\longrightarrow} 2 \mathrm{R}_{0}^{\cdot}$;

1a. $\mathrm{R}_{0}^{\cdot}+\mathrm{RH} \stackrel{k_{\mathrm{la}}}{\longrightarrow} \mathrm{R}_{0} \mathrm{H}+\mathrm{R}^{\cdot}$.

Chain propagation

2. $\mathrm{R}^{\cdot}+\mathrm{O}_{2} \stackrel{k_{2}}{\longrightarrow} \mathrm{RO}_{2}^{*}$;

3. $\mathrm{RO}_{2}^{\cdot}+\mathrm{RH} \stackrel{k_{3}}{\longrightarrow} \mathrm{RO}_{2} \mathrm{H}+\mathrm{R}^{\cdot}$ (or $\mathrm{ROH}+\mathrm{RO}^{*}$ );

3a. $\mathrm{RO}_{2}^{\cdot} \stackrel{k_{3 \mathrm{a}}}{\longrightarrow} \mathrm{R}_{(-\mathrm{H})}^{\prime} \mathrm{HO}+\mathrm{R}^{\prime \prime} \mathrm{O}^{\cdot}$ (or $\left.\mathrm{R}_{(-2 \mathrm{H})} \mathrm{HO}+{ }^{\circ} \mathrm{OH}\right)$;

3b. $\mathrm{R}^{\prime \prime} \mathrm{O}^{\cdot}\left(\mathrm{RO}^{*}\right)+\mathrm{RH} \stackrel{k_{3 \mathrm{~b}}}{\longrightarrow} \mathrm{R}^{\prime \prime} \mathrm{OH}(\mathrm{ROH})+\mathrm{R}^{\cdot}$

${ }^{1}$ The only difference between the kinetic model of oxidation and the kinetic model of the chain addition of 1-hydroxyalkyl radicals to the free (unsolvated) form of formaldehyde in nonmethanolic alcohol-formaldehyde systems $[1,15]$ is that in the former does not include the formation of the molecular 1:1 adduct via reaction 4 .

$$
\text { (or } \left.{ }^{\bullet} \mathrm{OH}+\mathrm{RH} \stackrel{k_{3 b}}{\longrightarrow} \mathrm{H}_{2} \mathrm{O}+\mathrm{R}^{\cdot}\right) \text {. }
$$

Inhibition

4. $\mathrm{RO}_{2}^{-}+\mathrm{O}_{2} \stackrel{k_{4}}{\longrightarrow} \mathrm{RO}_{4}^{\cdot}$.

Chain termination

5. $2 \mathrm{R} \cdot \stackrel{2 k_{5}}{\longrightarrow} \mathrm{RR}$

$$
\text { (or } \mathrm{R}_{(-2 \mathrm{H})} \mathrm{H}+\mathrm{RH} \text { ); }
$$

6. $\mathrm{R}^{\cdot}+\mathrm{RO}_{4}^{\cdot} \stackrel{k_{6}}{\longrightarrow} \mathrm{RH}+\mathrm{R}_{(-2 \mathrm{H})} \mathrm{HO}+\mathrm{O}_{3}$

(or: $\mathrm{ROH}+\mathrm{R}_{(-2 \mathrm{H})} \mathrm{HO}+\mathrm{O}_{2}$,

$\mathrm{ROR}+\mathrm{O}_{3}$,

$\left.\mathrm{RO}_{2} \mathrm{R}+\mathrm{O}_{2}\right)$;

7. $2 \mathrm{RO}_{4}^{\cdot} \stackrel{2 k_{7}}{\longrightarrow} \mathrm{RO}_{2} \mathrm{R}+2 \mathrm{O}_{3}$.

The chain evolution stage of Scheme 1 includes consecutive reaction pairs 2,3 ; 2, 3a, and 3a, 3b; parallel (competing) reaction pairs $3,3 \mathrm{a} ; 3,3 \mathrm{~b} ; 3,4$, and $3 \mathrm{a}, 4$; and consecutive-parallel reactions 2 and 4 .

The decomposition of the initiator $\mathrm{I}$ in reaction 1 yields a reactive $\mathrm{R}_{0}^{*}$ radical, which turns into the ultimate product $\mathrm{R}_{0} \mathrm{H}$ via reaction 1a, generating an alkyl radical $\mathrm{R}^{*}$, which participates in chain propagation. In reaction 2 , the addition of the free radical $\mathrm{R}^{\cdot}$ to the oxygen molecule yields a reactive alkylperoxyl 1:1 adduct radical $\mathrm{RO}_{2}^{\bullet}$ [10], which possesses increased energy owing to the energy released upon the conversion of the $\mathrm{O}=\mathrm{O}$ bond into the ordinary bond $\mathrm{RO}-\mathrm{O}^{*}$ (for addition in the gas phase under standard conditions, this energy is $115-130 \mathrm{~kJ} \mathrm{~mol}^{-1}$ for $\mathrm{C}_{1}-\mathrm{C}_{4}$ alkyl radicals $[6,16,17]$ and $73 \mathrm{~kJ} \mathrm{~mol}^{-1}$ for the allyl radical [17]). Because of this, the adduct radical can decompose (reaction 3a) or react with some neighbor molecule (reaction 3 or 4 ) on the spot, without diffusing in the solution and, accordingly, without entering into any chain termination reaction. In reaction 3 , the interaction between the radical adduct $\mathrm{RO}_{2}^{\circ}$ and the hydrocarbon molecule RH yields, via a chain mechanism, the alkyl hydroperoxide $\mathrm{RO}_{2} \mathrm{H}$ (this reaction regenerates the chain carrier $\mathrm{R}^{\bullet}$ and, under certain conditions, can be viewed as being reversible [6]) or the alcohol $\mathrm{ROH}$ (this is followed by the regeneration of $\mathrm{R}^{\cdot}$ via reaction $3 b$ ). The latter (alternative) pathway of reaction 3 consists of four steps, namely, the breaking of old bonds and the formation of two new bonds in the reacting structures. In reaction $3 \mathrm{a}$, the isomerization and decomposition of the alkylperoxyl radical adduct $\mathrm{RO}_{2}^{\bullet}$ with $\mathrm{O}-\mathrm{O}$ and $\mathrm{C}-\mathrm{O}$ or $\mathrm{C}-\mathrm{H}$ bond breaking take place [5, 9], yielding the carbonyl compound $\mathrm{R}_{(-\mathrm{H})} \mathrm{HO}$ or $\mathrm{R}_{(-2 \mathrm{H})} \mathrm{HO}$. Reaction $3 \mathrm{~b}$ produces the alcohol $\mathrm{R}^{\prime \prime} \mathrm{OH}$ or water and regenerates the free radical $\mathrm{R}^{\cdot}$ (here, $\mathrm{R}^{\prime}$ and $\mathrm{R}^{\prime \prime}$ are radicals having a smaller number of carbon atoms than R). As follows from the above scheme of the 
process, consecutive reactions $3 \mathrm{a}$ and $3 \mathrm{~b}$ (whose rates are equal within the quasi-steady-state treatment), in which the highly reactive fragment, oxyl radical $\mathrm{R}^{\prime \prime} \mathrm{O}^{\bullet}$ (or ${ }^{\circ} \mathrm{OH}$ ) forms and then disappears, respectively, can be represented as a single, combined bimolecular reaction $3 \mathrm{a}, \mathrm{b}$ occurring in a "cage" of solvent molecules. Likewise, the alternative (parenthesized) pathways of reactions 3 and $3 b$, which involve the alkoxyl radical $\mathrm{RO}^{\circ}$, can formally be treated as having equal rates. For simple alkyl $\mathrm{C}_{1}-\mathrm{C}_{4}$ radicals $\mathrm{R}$, the pathway of reaction 3 leading to the alkyl hydroperoxide $\mathrm{RO}_{2} \mathrm{H}$ is endothermic $\left(\Delta H_{298}^{\circ}=30-80 \mathrm{~kJ} \mathrm{~mol}^{-1}\right)$ and the alternative pathway yielding the alcohol $\mathrm{ROH}$ is exothermic $\left(\Delta H_{298}^{\circ}=-120\right.$ to $\left.-190 \mathrm{~kJ} \mathrm{~mol}^{-1}\right)$, while the parallel reaction $3 \mathrm{a}$, which yields a carbonyl compound and the alkoxyl radical $\mathrm{R}^{\prime \prime} \mathrm{O}^{*}$ or the hydroxyl radical $\mathrm{HO}^{*}$,

is exothermic in both cases $\left(\Delta H_{298}^{\circ}=-80\right.$ to $-130 \mathrm{~kJ}$ $\left.\mathrm{mol}^{-1}\right)$, as also is reaction $3 \mathrm{~b}\left(\Delta H_{298}^{\circ}=-10\right.$ to $-120 \mathrm{~kJ}$ $\mathrm{mol}^{-1}$ ), consecutive to reaction $3 \mathrm{a}$, according to thermochemical data for the gas phase [6, 17, 18]. In reaction 4 , which is competing with (parallel to) reactions 3 and $3 \mathrm{a}$ (chain propagation through the reactive radical $\mathrm{R}^{*}$ ), the resulting low-reactive radical that does not participate in further chain propagation and inhibits the chain process is supposed to be the alkyltetraoxyl 1:2 radical adduct ${ }^{2,3} \mathrm{RO}_{4}^{\bullet}$, which has the largest weight and

${ }^{2}$ It is hypothesized that raising the oxygen concentration in the $o$-xylene-oxygen system can lead to the formation of an $\left[\mathrm{ROO}^{*} \cdot \mathrm{O}_{2}\right]$ intermediate complex [11] similar to the $\left[\mathrm{ROO}^{\circ} \cdots(\pi\right.$-bond $\left.) \mathrm{RH}\right]$ complex between the alkylperoxyl 1:1 adduct radical and an unsaturated hydrocarbon suggested in this work. The electronic structure of the $\pi$-complexes is considered elsewhere [19].

${ }^{3}$ Thermochemical data are available for some polyoxyl free radicals (the enthalpy of formation of the methyltetraoxyl radical without the energy of the possible intramolecular hydrogen bond $\mathrm{H} \cdots \mathrm{O}$ taken into account is $\left.\Delta H_{f}{ }^{\circ} 298\left(\mathrm{CH}_{3} \mathrm{O}_{4}^{\circ}\right)=121.3 \pm 15.3 \mathrm{~kJ} \mathrm{~mol}^{-1}\right)$ and polyoxides $\left(\Delta H_{f}{ }_{298}\left(\mathrm{CH}_{3} \mathrm{O}_{4} \mathrm{H}\right)=-21.0 \pm 9 \mathrm{~kJ} \mathrm{~mol}^{-1}\right)$ [20]. These data were obtained using the group contribution approach. Some physicochemical and geometric parameters were calculated for the methyl hydrotetraoxide molecule as a model compound [21-23]. The IR spectra of dimethyl tetraoxide with isotopically labeled groups in $\mathrm{Ar}-\mathrm{O}_{2}$ matrices were also reported [24]. For reliable determination of the number of oxygen atoms in an oxygen-containing species, it is necessary to use IR and EPR spectroscopy in combination with the isotope tracer method [24]. size. This radical is possibly stabilized by a weak intramolecular $\mathrm{H} \cdots \mathrm{O}$ hydrogen bond [25] shaping it into a six-membered cyclic structure ${ }^{4}$ (seven-membered cyclic structure in the case of aromatic and certain branched acyclic hydrocarbons) [27, 28]:

$$
\text { 4. } \mathrm{RO}_{2}^{\dot{1}}+\mathrm{O}_{2} \stackrel{k_{4}}{\longrightarrow}[\underbrace{\mathrm{R}_{(-\mathrm{H})}^{\mathrm{O}}-\mathrm{O}}_{\mathrm{H} \cdots \mathrm{O}}]^{*} \equiv\left[\mathrm{R}_{(-\mathrm{H})} \mathrm{H}^{*} \mathrm{O}_{4}\right]^{*} \text {. }
$$

Reaction 4 in the case of the methylperoxyl radical $\mathrm{CH}_{3} \mathrm{O}_{2}^{\bullet}$ adding to the oxygen molecule to yield the methyltetraoxyl radical $\mathrm{CH}_{3} \mathrm{O}_{4}^{\bullet}$ takes place in the gas phase, with heat absorption equal to $110.0 \pm 18.6 \mathrm{~kJ} \mathrm{~mol}^{-1}$ [20] (without the energy of the possible formation of a hydrogen bond taken into account). The exothermic reactions 6 and 7, in which the radical $\mathrm{R}^{\bullet}$ or $\mathrm{RO}_{4}^{\bullet}$ undergoes disproportionation, include the isomerization and decomposition of the $\mathrm{RO}_{4}^{\bullet}$ radical. ${ }^{5}$ The latter process is likely accompanied by chemiluminescence typical of hydrocarbon oxidation [23]. These reactions regenerate oxygen as $\mathrm{O}_{2}$ molecules (including singlet oxygen ${ }^{6}[23,30]$ ) and, partially, as $\mathrm{O}_{3}$ molecules and yield the carbonyl compound $\mathrm{R}_{(-2 \mathrm{H})} \mathrm{HO}$ (possibly in the triplet excited state [23]). Depending on the decomposition pathway, the other possible products are the alcohol $\mathrm{ROH}$, the ether ROR, and the alkyl peroxide $\mathrm{RO}_{2} \mathrm{R}$. It is likely that the isomerization and decomposition of the $\mathrm{RO}_{4}^{\circ}$ radical via reactions 6 and 7 can take place through the breaking of a $\mathrm{C}-\mathrm{C}$ bond to yield carbonyl compounds, alcohols, ethers, and organic peroxides containing fewer carbon atoms than the initial hydrocarbon, as in the case of the alkylperoxyl radical $\mathrm{RO}_{2}^{*}$ in reaction 3a. At later stages of oxidation and at sufficiently high temperatures, the resulting aldehydes can be further oxidized into respective carboxylic acids. They can also react with molecular oxygen so that a $\mathrm{C}-\mathrm{H}$ bond in the aldehyde molecule breaks to yield two free radicals $\left(\mathrm{HO}_{2}^{\cdot}\right.$ and ${ }^{\cdot} \mathrm{R}_{(-\mathrm{H})} \mathrm{O}$ or $\left.{ }^{\circ} \mathrm{R}_{(-2 \mathrm{H})} \mathrm{O}\right)$. This process, like possible ozone decomposition yielding an

${ }^{4}$ The $\widehat{\mathrm{R}}_{(-\mathrm{H})} \mathrm{H} \cdots \mathrm{O}(\mathrm{R}) \mathrm{O}_{3}$ ring consisting of the same six atoms $(\mathrm{C}, \mathrm{H}$, and $4 \mathrm{O})$, presumably with a hydrogen bond [5], also forms in the transition state of the dimerization of alkylperoxyl radicals $\mathrm{RO}_{2}^{\cdot}$ via the Russell mechanism [7, 26].

${ }^{5}$ Taking into account the principle of detailed balance for the various pathways of formation of products, whose numbers in the elementary reaction should not exceed three for possible involvement in the triple collisions in the case of the reverse reaction, since the probability of simultaneous interaction of four particles is negligible. This principle was not taken into account in the author's works on oxidation until 2012.

${ }^{6}$ Note that the alkylperoxyl radicals $\mathrm{RO}_{2}$ are effective quenchers of singlet oxygen $\mathrm{O}_{2}\left(a^{1} \Delta_{g}\right)$ [29]. 
${ }^{\circ} \mathrm{O} \cdot$ atom or peroxide decomposition with $\mathrm{O}-\mathrm{O}$ bond breaking, leads to degenerate chain branching [5].

The kinetic equations describing the rates of formation of molecular products at the chain propagation and termination stages of the above reaction Scheme 1 were obtained using the quasi-steady-state treatment. To simplify the writing of equations in the derivation process, we introduce the following notations: $l=[\mathrm{RH}]$ and $x=$ $\left[\mathrm{O}_{2}\right] ; \mathrm{R}_{1}=\mathrm{R}^{\bullet}, \mathrm{R}_{2}=\mathrm{RO}_{4}^{\circ}, \mathrm{R}_{3}=\mathrm{RO}_{2}^{\cdot}$, and $\mathrm{R}_{4}=\mathrm{R}^{\prime \prime} \mathrm{O}^{\bullet}$ (or $\cdot \mathrm{OH}) ; \alpha=k_{3} / k_{4}$ and $\left.\beta=k_{3 \mathrm{a}} / k_{4}(\mathrm{~mol} \mathrm{dm})^{-3}\right)$. According to Scheme 1, $V_{1}=V_{1 \mathrm{a}}, V_{3 \mathrm{a}}=V_{3 \mathrm{~b}}$, and $V_{2}=V_{3}+V_{3 \mathrm{a}}+V_{4}$. In order to reduce the exponent of the $2 k_{5}\left[\mathrm{R}^{\circ}\right]^{2}$ term in the $d\left[\mathrm{R}^{*}\right] / d t=0$ equation to unity [1], were used the following condition for the early stages of the process: $k_{6}=$ $\sqrt{2 k_{5} 2 k_{7}} \quad$ [8] and, hence, $V_{1}=V_{5}+2 V_{6}+V_{7}=\left(\sqrt{2 k_{5}} \mathrm{R}_{1}\right.$ $\left.+\sqrt{2 k_{7}} \mathrm{R}_{2}\right)^{2}$ and $\sqrt{V_{1}}=\left(\sqrt{2 k_{5}} \mathrm{R}_{1}+\sqrt{2 k_{7}} \mathrm{R}_{2}\right)$.

Denote $\delta_{1}=\sqrt{2 k_{5} V_{1}}$ and $\delta_{2}=\sqrt{2 k_{7} V_{1}}$ and obtain the following expressions for free radicals.

$$
\begin{aligned}
& d\left[\mathrm{R}_{3}\right] / d t=V_{2}-V_{3}-V_{3 \mathrm{a}}-V_{4}=k_{2} \mathrm{R}_{1} x-k_{3} \mathrm{R}_{3} l-k_{3 \mathrm{a}} \mathrm{R}_{3}- \\
& k_{4} \mathrm{R}_{3} x=k_{2} \mathrm{R}_{1} x-\left(k_{3} l+k_{3 \mathrm{a}}+k_{4} x\right) \mathrm{R}_{3}=0 \text {; } \\
& \mathrm{R}_{3}=\frac{k_{2} \mathrm{R}_{1} x}{\left(k_{3} l+k_{3 a}+k_{4} x\right)} . \\
& d\left[\mathrm{R}_{2}\right] / d t=V_{4}-2 V_{6}-V_{7}=k_{4} \mathrm{R}_{3} x-\delta_{2} \mathrm{R}_{2}=\frac{k_{2} \mathrm{R}_{1} x^{2}}{(\alpha l+\beta+x)} \\
& -\delta_{2} \mathrm{R}_{2}=k_{2} \mathrm{R}_{1} x^{2}-(\alpha l+\beta+x) \delta_{2} \mathrm{R}_{2}=0 ; \\
& \mathrm{R}_{2}=\frac{k_{2} \mathrm{R}_{1} x^{2}}{(\alpha l+\beta+x) \delta_{2}} . \\
& d\left[\mathrm{R}_{1}\right] / d t=V_{1}-V_{2}+V_{3}+V_{3 \mathrm{a}}-V_{5}-2 V_{6}=V_{1}-k_{2} \mathrm{R}_{1} x+ \\
& k_{3} \mathrm{R}_{3} l+k_{3 \mathrm{a}} \mathrm{R}_{3}-\delta_{1} \mathrm{R}_{1}=V_{1}-k_{2} \mathrm{R}_{1} x+\frac{k_{2} \mathrm{R}_{1} \alpha l x}{(\alpha l+\beta+x)}+ \\
& \frac{k_{2} \mathrm{R}_{1} \beta x}{(\alpha l+\beta+x)}-\delta_{1} \mathrm{R}_{1}=V_{1}(\alpha l+\beta+x)-\left[k_{2} x(\alpha l+\beta+x)\right. \\
& \left.-k_{2} \alpha l x-k_{2} \beta x+(\alpha l+\beta+x) \delta_{1}\right] \mathrm{R}_{1}=V_{1}(\alpha l+\beta+x)-\left[k_{2} x^{2}\right. \\
& \left.+(\alpha l+\beta+x) \delta_{1}\right] \mathrm{R}_{1}=0 \text {; } \\
& \mathrm{R}_{1}=\frac{V_{1}(\alpha l+\beta+x)}{k_{2} x^{2}+(\alpha l+\beta+x) \delta_{1}} . \\
& V_{3}=k_{3} \mathrm{R}_{3} l=\frac{k_{2} \mathrm{R}_{1} \alpha l x}{(\alpha l+\beta+x)}=\frac{V_{1} \alpha l k_{2} x}{k_{2} x^{2}+(\alpha l+\beta+x) \sqrt{2 k_{5} V_{1}}} . \\
& V_{3 \mathrm{a}}=k_{3 \mathrm{a}} \mathrm{R}_{3}=\frac{k_{2} \mathrm{R}_{1} \beta x}{(\alpha l+\beta+x)}=\frac{V_{1} \beta k_{2} x}{k_{2} x^{2}+(\alpha l+\beta+x) \sqrt{2 k_{5} V_{1}}} . \\
& V_{5}=2 k_{5} \mathrm{R}_{1}^{2}, 2 V_{6}=2 k_{6} \mathrm{R}_{1} \mathrm{R}_{2} \text {, and } V_{7}=2 k_{7} \mathrm{R}_{2}^{2} \text {. }
\end{aligned}
$$

The rate constant $k_{2}$ of reaction 2 in the kinetic equations can be replaced with its analytical expression, which is obtained by solving the quadratic equation following from the rate function extremum condition

$\partial V_{3,3 \mathrm{a}}(1: 1$ Adduct $) / \partial x=0$.

$V_{3,3 \mathrm{a}}=V_{3}+V_{3 \mathrm{a}}=\frac{V_{1}(\alpha l+\beta) k_{2} x}{k_{2} x^{2}+(\alpha l+\beta+x) \delta_{1}}=\frac{\mathrm{D} x}{\mathrm{~A} x^{2}+\mathrm{B} x+\mathrm{C}}$,

where $\mathrm{D}=V_{1}(\alpha l+\beta) k_{2}, \mathrm{~A}=k_{2}, \mathrm{~B}=\delta_{1}$, and $\mathrm{C}=(\alpha l+\beta) \delta_{1}$,

$\partial V_{3,3 \mathrm{a}} / \partial x=\mathrm{D}\left(\mathrm{A} x^{2}+\mathrm{B} x+\mathrm{C}\right)-\mathrm{D} x(2 \mathrm{~A} x+\mathrm{B})=-\mathrm{A} x^{2}+\mathrm{C}$

$=-k_{2} x^{2}+(\alpha l+\beta) \delta_{1}=0$.

The solution of this incomplete quadratic equation gives the value of the concentration $x_{m}$ at the maximum point:

$$
x_{\mathrm{m}}=\sqrt{\frac{\left(\alpha l_{m}+\beta\right) \delta_{1}}{k_{2}}} .
$$

From here, the following kinetic equations of oxidation reaction rates were obtained.

$$
\begin{gathered}
\begin{array}{c}
V_{3}\left(\mathrm{RO}_{2} \mathrm{H} ; \mathrm{ROH}\right)= \\
V_{1} \alpha l k_{2} x / f= \\
V_{1} \alpha l x / f_{m}
\end{array} \\
\begin{array}{r}
V_{3 \mathrm{a}}\left(\mathrm{R}_{(-\mathrm{H})}^{\prime} \mathrm{HO} ; \mathrm{R}_{(-2 \mathrm{H})} \mathrm{HO}\right)= \\
V_{3 \mathrm{~b}}\left(\mathrm{R}^{\prime \prime} \mathrm{OH} ; \mathrm{H}_{2} \mathrm{O}\right)= \\
V_{1} \beta k_{2} x / f= \\
V_{1} \beta x / f_{m}
\end{array} \\
V_{5}=V_{1}^{2} 2 k_{5}(\alpha l+\beta+x)^{2} / f^{2} \\
2 V_{6}=2 V_{1} \sqrt{2 k_{5} V_{1}}(\alpha l+\beta+x) k_{2} x^{2} / f^{2} \\
V_{7}=V_{1}\left(k_{2} x^{2}\right)^{2} / f^{2}
\end{gathered}
$$

where $V_{1}$ is the initiation rate, $l=[\mathrm{RH}]$ and $x=\left[\mathrm{O}_{2}\right]$ are the molar concentrations of the starting components $(l>x), \alpha$ $=k_{3} / k_{4}$ and $\left.\beta=k_{3 \mathrm{a}} / k_{4}(\mathrm{~mol} \mathrm{dm})^{-3}\right)$ are the ratios of the rate constants of the competing (parallel) reactions, $k_{2}=\left(\alpha l_{m}+\beta\right) \sqrt{2 k_{5} V_{1}} / x_{m}^{2}$ is the rate constant of the addition of the alkyl radical $\mathrm{R}^{\cdot}$ to the oxygen molecule (reaction 2) as determined by solving the quadratic equation following from the rate function extremum condition $\partial V_{3,3 \mathrm{a}} / \partial x=0, l_{m}$ and $x_{m}$ are the values of $l$ and $x$ at the maximum point of the function,

$$
\begin{aligned}
& f=k_{2} x^{2}+(\alpha l+\beta+x) \sqrt{2 k_{5} V_{1}}, \text { and } \\
& f_{m}=x^{2}+(\alpha l+\beta+x) x_{m}^{2} /\left(\alpha l_{m}+\beta\right) .
\end{aligned}
$$

The ratios of the rates of the competing reactions are $V_{3} / V_{4}$ $=\alpha l / x$ and $V_{3 \mathrm{a}} / V_{4}=\beta / x$, and the chain length is $v=\left(V_{3}+\right.$ $\left.V_{3 a}\right) / V_{1}$. The overall rate of the process is a complicated function of the formation and disappearance rates of the free radicals $\mathrm{R}^{\cdot}$ and $\mathrm{RO}_{4}^{\bullet}: V\left(\mathrm{RO}_{2} \mathrm{H}, \mathrm{R}_{(-\mathrm{H})}^{\prime} \mathrm{HO}, \mathrm{R}^{\prime \prime} \mathrm{OH}\right.$; $\left.\mathrm{ROH} ; \mathrm{R}_{(-2 \mathrm{H})} \mathrm{HO}, \mathrm{H}_{2} \mathrm{O}\right)=V_{1 \mathrm{a}}+V_{3}+V_{3 \mathrm{~b}}-V_{4}-V_{5}-V_{7}$. As distinct from the rates $V_{4}\left(V_{4} \leq V_{1}\right), V_{5}$, and $V_{7}$, the rates $V_{2}$, $V_{3}, V_{3 \mathrm{a}, 3 \mathrm{~b}}$, and $2 V_{6}$ as a function of the concentration $x$ have a maximum.

Eqs. (1a) and (2a) were obtained by replacing the rate constant $k_{2}$ in Eqs. (1) and (2) with its analytical expression (for reducing the number of unknown parameters to be determined directly).

For $\alpha l \gg \beta\left(V_{3} \gg V_{3 a}\right)$, when the total yield of alkyl 
hydroperoxides and alcohols having the same number of carbon atoms as the initial compound far exceeds the yield of carbonyl compounds, as in the case of the oxidation of some hydrocarbons, the parameter $\beta$ in Eqs. (1) and (1a) can be neglected $(\beta=0): f=k_{2} x^{2}+(\alpha l+x) \sqrt{2 k_{5} V_{1}}$, $f_{m}=x^{2}+(\alpha l+x) x_{m}^{2} / \alpha l_{m}$, and $k_{2}=\alpha l_{m} \sqrt{2 k_{5} V_{1}} / x_{m}^{2}$.

Equations (1) and (2) subject to the constraint $k_{2} x^{2} \gg(\alpha l+$ $\beta+x) \sqrt{2 k_{5} V_{1}}$ (the descending branch of the peaking curve) can be transformed into Eqs. (6) and (7), respectively, which express simple inverse proportionalities with respect to the oxygen concentration $x$ and allow the parameters $\alpha$ and $\beta$ to be tentatively estimated from the experimental product formation rate $V$ provided that $V_{1}$ is known:

$$
\begin{aligned}
& V_{3}=V_{1} \alpha l / \varphi x, \\
& V_{3 a}=V_{1} \beta / \varphi x,
\end{aligned}
$$

where $\varphi=2$ at the point of maximum (where $k_{2} x^{2} \cong(\alpha l+\beta$ $+x) \sqrt{2 k_{5} V_{1}}$ ) and $\varphi=1$ for the descending branch of the curve.

In the alternative kinetic model of oxidation, whose chain termination stage involves, in place of $\mathrm{R}^{\circ}$ (Scheme 1), $\mathrm{RO}_{2}^{*}$ radicals reacting with one another and with $\mathrm{RO}_{4}^{\circ}$ radicals, the dependences of the chain formation rates of the products on the oxygen concentration $x$ derived by the same method have no maximum: $V_{3}=V_{1} k_{3} l /\left(k_{4} x+\sqrt{\left.2 k_{5_{1}} V_{1}\right)}\right.$ and $V_{3 \mathrm{a}}=V_{1} k_{3 \mathrm{a}} /\left(k_{4} x+\sqrt{2 k_{5} V_{1}}\right)$. In the kinetic model of oxidation that does not include the competing reaction $4\left(k_{4}=0\right)$ and involves the radicals $\mathrm{R}^{\cdot}$ and $\mathrm{RO}_{2}^{-}$(the latter instead of $\mathrm{RO}_{4}^{\circ}$ in Scheme 1) in reactions 5-7, the reaction rate functions $V_{3}$ and $V_{3 \mathrm{a}}$ obtained in the same way are fractional rational functions in the form of $a_{0} x /\left(b_{0} x+c_{0}\right)$, where $a_{0}, b_{0}$, and $c_{0}$ are coefficients having no extremum. For a similar kinetic model in which reactions $3 \mathrm{a}, \mathrm{b}$ and 4 appearing in the above scheme are missing $\left(k_{3 \mathrm{a}}=k_{4}=0\right)$, Walling [7], using the quasi-steady-state treatment in the long kinetic chain approximation, when it can be assumed that $V_{2}=V_{3}$, without using the substitution $k_{6}=\sqrt{2 k_{5} 2 k_{7}} \quad[5,7,8]$ (as distinct from this work), found that $V_{2}=V_{3}$ is an irrational function of $x: a_{1} x / \sqrt{b_{1} x^{2}+c_{1} x+d_{1}}$ where $a_{1}$, $b_{1}, c_{1}$, and $d_{1}$ are coefficients. Again, this function has no maximum with respect to the concentration of any of the two components.

Thus, of the three kinetic models of oxidation mathematically analyzed above, which involve the radicals $\mathrm{R}^{\cdot}$ and $\mathrm{RO}_{2}^{*}$ in three types of quadratic-law chain termination reactions (reactions 5-7) and are variants of the conventional model [5-10], the last two lead to an oxidation rate versus oxygen concentration curve that emanates from the origin of coordinates, is convex upward, and has an asymptote parallel to the abscissa axis. Such monotonic dependences are observed when the oxygen solubility in the liquid is limited under given experimental conditions and the oxygen concentration attained ${ }^{7}$ is $\left[\mathrm{O}_{2}\right]_{\text {top }} \leq x_{\mathrm{m}}$.

Unlike the conventional model, the above kinetic model of free-radical nonbranched-chain oxidation, which includes the pairs of competing reactions 3, 4 and 3a, 4 (Scheme 1), allows us to describe the nonmonotonic (peaking) dependence of the oxidation rate on the oxygen concentration (Fig. 1). In this oxidation model, as the oxygen concentration in the binary system is increased, oxygen begins to act as an oxidation autoinhibitor or an antioxidant via the further oxidation of the alkylperoxyl 1:1 adduct radical $\mathrm{RO}_{2}^{*}$ into the low-reactive $1: 2$ adduct radical $\mathrm{RO}_{4}^{\circ}$ (reactions 4 and 6 lead to inefficient consumption of the free radicals $\mathrm{RO}_{2}^{*}$ and $\mathrm{R}^{\cdot}$ and cause shortening of the kinetic chains). The optimum oxygen concentration $x_{m}$, at which the oxidation rate is the highest, can be calculated using kinetic equations (1a) and (2a) or the corresponding analytical expression for $k_{2}$. In the familiar monograph "Chain Reactions" by Semenov [31], it is noted that raising the oxygen concentration when it is already sufficient usually slows down the oxidation process by shortening the chains. The existence of the upper (second) ignition limit in oxidation is due to chain termination in the bulk through triple collisions between an active species of the chain reaction and two oxygen molecules (at sufficiently high oxygen partial pressures). In the gas phase at atmospheric pressure, the number of triple collisions is roughly estimated to be $10^{3}$ times smaller than the number of binary collisions (and the probability of a reaction taking place depends on the specificity of the action of the third particle). Note that in the case of a gas-phase oxidation of hydrogen at low pressures of 25-77 Pa and a temperature of $77 \mathrm{~K}$ [12] when triple collisions are unlikely, the dependence of the rate of hydrogen peroxide formation on oxygen concentration (the rate of passing of molecular oxygen via the reaction tube) also has a pronounced maximum (see curves 3 and 4 in Fig. 2) that indicates a chemical mechanism providing the appearance of a maximum (see reaction 4 of Scheme 2).

Curve 1 in Fig. 1 illustrates the fit between Eq. (1a) at $\alpha l$ $>\beta$ and experimental data for the radiation-induced oxidation of $o$-xylene in the liquid phase at $373 \mathrm{~K}$ in the case of 2-methylbenzyl hydroperoxide forming much more rapidly than $o$-tolualdehyde $\left(V_{3} \gg V_{3 \text { a }}\right.$ and $\alpha l>\beta$, i.e., the parameter $\beta$ can be neglected) [11]. The oxygen

${ }^{7}$ The oxygen concentration attained in the liquid may be below the thermodynamically equilibrium oxygen concentration because of diffusion limitations hampering the establishment of the gas-liquid saturated solution equilibrium under given experimental conditions (for example, when the gas is bubbled through the liquid) or because the Henry law is violated for the given gas-liquid system under real conditions. 
concentration limit in $o$-xylene is reached at an oxygen concentration of $\left[\mathrm{O}_{2}\right]_{\text {top }}>x_{m}$, which corresponds to the third experimental point [11]. The oxygen concentration was calculated from the oxygen solubility in liquid xylene at $373 \mathrm{~K}$ [32]. The following quantities were used in this mathematical description: ${ }^{60} \mathrm{Co} \gamma$-radiation dose rate of $P=$ $2.18 \mathrm{~Gy} \mathrm{~s}^{-1}$ and total initiation yield of $G\left(o-\mathrm{CH}_{3} \mathrm{C}_{6} \mathrm{H}_{4} \dot{\mathrm{C}} \mathrm{H}_{2}\right)$ $=2.6$ particles per $100 \mathrm{eV}$ of the energy absorbed by the solution [11]; $V_{1}=4.73 \times 10^{-7} \mathrm{~mol} \mathrm{dm}^{-3} \mathrm{~s}^{-1}$, and $2 k_{5}=1.15$ $\times 10^{10} \mathrm{dm}^{3} \mathrm{~mol}^{-1} \mathrm{~s}^{-1}$. The resulting value of the parameter $\alpha$ is $(9.0 \pm 1.8) \times 10^{-3}$; hence, $k_{2}=(3.2 \pm 0.8) \times 10^{5} \mathrm{dm}^{3}$ $\mathrm{mol}^{-1} \mathrm{~s}^{-1}$. From the data presented in [33], it was estimated that $k_{4}=k_{3} / \alpha=(5.2 \pm 1.2) \times 10^{2} \mathrm{dm}^{3} \mathrm{~mol}^{-1} \mathrm{~s}^{-1}$.

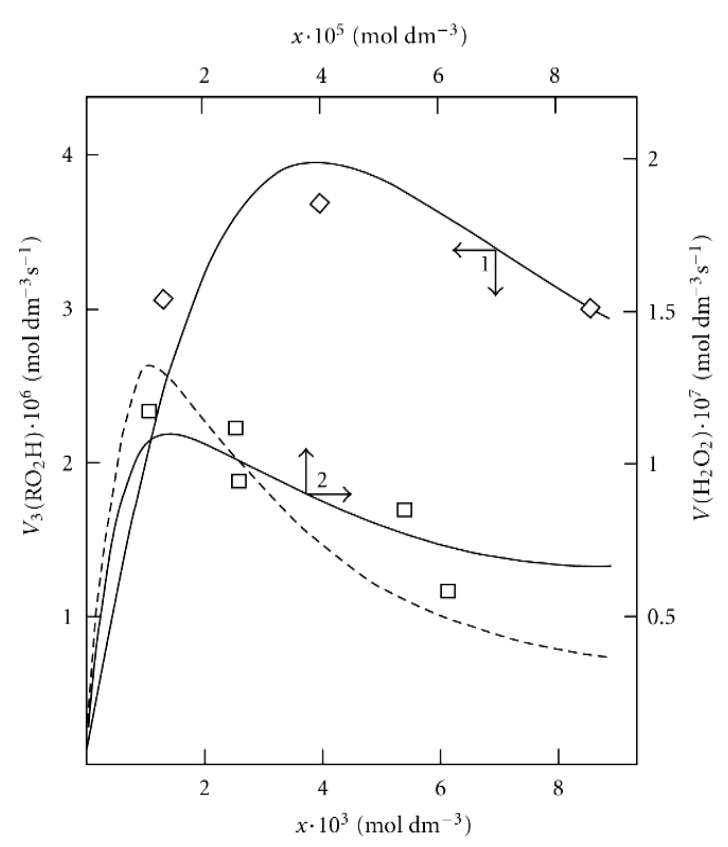

Figure 1: $(1, \diamond)$ Reconstruction of the functional dependence of the 2-methylbenzyl hydroperoxide formation rate $V_{3}\left(\mathrm{RO}_{2} \mathrm{H}\right)$ on the dissolved oxygen concentration $x$ from empirical data (points) using Eq. (1a) with $\beta=0$ (model optimization with respect to the parameter $\alpha$ ) for the $o$-xylene-oxygen system at $373 \mathrm{~K}$ [11] (standard deviation of $\left.S_{Y}=5.37 \times 10^{-7}\right) .(2, \square)$ Reconstruction of the functional dependence of the total hydrogen peroxide formation rate $V_{3}, 7_{7}\left(\mathrm{H}_{2} \mathrm{O}_{2}\right)$ on the dissolved oxygen concentration $x$ from empirical data (symbols) using Eqs. (1a) and (5a) with $\beta=0$ (model optimization with respect to the parameter $\alpha$ ) for the $\gamma$-radiolysis of water saturated with hydrogen and containing different amounts of oxygen at $296 \mathrm{~K} \mathrm{[34]} \mathrm{(} S_{Y}=$ $\left.1.13 \times 10^{-8}\right)$. The dashed curve described $V_{3}\left(\mathrm{H}_{2} \mathrm{O}_{2}\right)$ as a function of the oxygen concentration $x$ based on Eq. (1a) with $\beta=0$ (model optimization with respect to $\alpha$ ) and the experimental data of curve $2\left(S_{Y}=1.73 \times 10^{-8}\right)$.

\section{ADDITION OF THE HYDROGEN ATOM}

A number of experimental findings concerning the autoinhibiting effect of an increasing oxygen concentration at modest temperatures on hydrogen oxidation both in the gas phase [12, 35, 36] (Fig. 2) and in the liquid phase [34] (Fig. 1, curve 2), considered in our earlier works [13, 27, $28,37]$, can also be explained in terms of the competition kinetics of free radical addition [14, 38]. From Fig. 2 shows that the quantum yields of hydrogen peroxide and water (of products of photochemical oxidation of hydrogen at atmospheric pressure and room temperature) are maximum in the region of small concentrations of oxygen in the hydrogen-oxygen system (curves 1 and 2, respectively) [35].

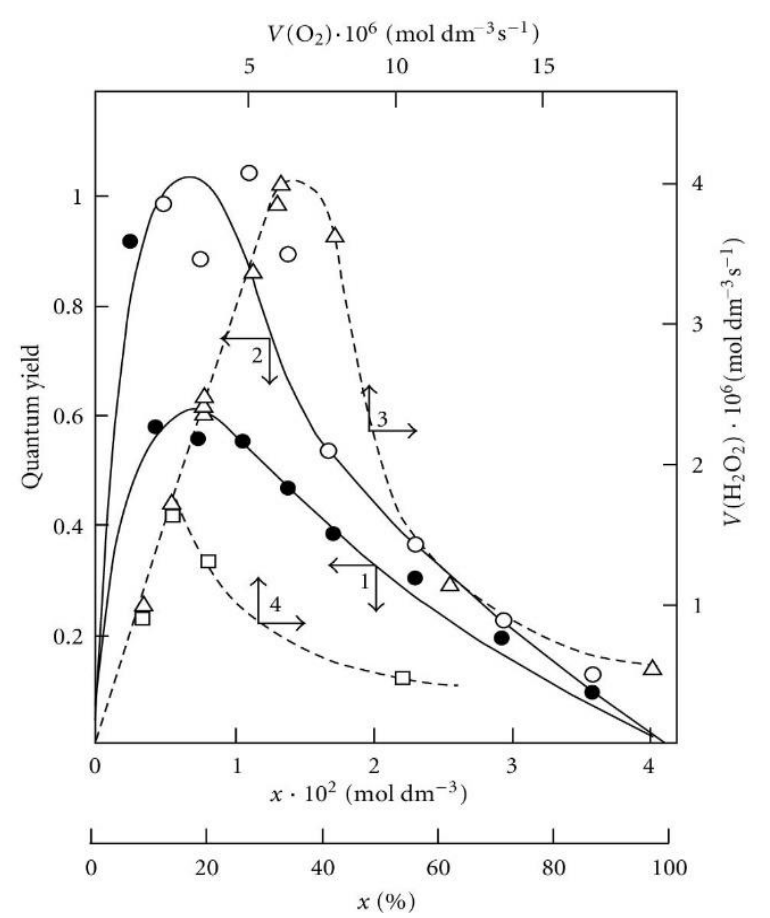

Figure 2: $(1,2)$ Quantum yields of $(1, \bullet)$ hydrogen peroxide and $(2, \circ)$ water resulting from the photochemical oxidation of hydrogen in the hydrogen-oxygen system as a function of the oxygen concentration $\mathrm{x}$ (light wavelength of 171.9-172.5 nm, total pressure of $10^{5} \mathrm{~Pa}$, room temperature [35]). $(3,4)$ Hydrogen peroxide formation rate $V\left(\mathrm{H}_{2} \mathrm{O}_{2}\right)$ (dashed curves) as a function of the rate $V\left(\mathrm{O}_{2}\right)$ at which molecular oxygen is passed through a gas-discharge tube filled with $(3, \triangle)$ atomic and $(4, \square)$ molecular hydrogen. Atomic hydrogen was obtained from molecular hydrogen in the gas-discharge tube before the measurements (total pressure of 25-77 Pa, temperature of $77 \mathrm{~K}[12])$. The symbols represent experimental data.

\section{Scheme 2}

Nonbranched-chain oxidation of hydrogen and changes in enthalpy $\left(\Delta H_{298}^{\circ}, \mathrm{kJ} \mathrm{mol}^{-1}\right)$ for elementary reactions ${ }^{8}$

\footnotetext{
${ }^{8}$ According to Francisco and Williams [20], the enthalpy of formation $\left(\Delta H_{f}^{\circ} 298\right)$ in the gas phase of $\mathrm{H}^{*}, \mathrm{HO}^{*}, \mathrm{HO}_{2}^{*}$,
} 
Chain initiation

1. $\mathrm{H}_{2} \stackrel{h v, \gamma}{\longrightarrow} 2 \mathrm{H}^{\circ}$ $\Delta H_{298}^{\circ}=436.0 \pm 0.0$.

Chain propagation

2. $\mathrm{H}^{\cdot}+\mathrm{O}_{2} \stackrel{k_{2}}{\longrightarrow} \mathrm{HO}_{2}^{\bullet}$,

$\Delta H_{298}^{\circ}=-205.4 \pm 1.7$;

3. $\mathrm{HO}_{2}^{\bullet}+\mathrm{H}_{2} \stackrel{k_{3}}{\longrightarrow} \mathrm{H}_{2} \mathrm{O}+\mathrm{HO}^{\circ}$,

$\Delta H^{\circ}{ }_{298}=-215.4 \pm 2.9$

(or $\mathrm{H}_{2} \mathrm{O}_{2}+\mathrm{H}^{\bullet}$ ),

$\Delta H^{\circ}{ }_{298}=69.4 \pm 1.7$;

$3^{\prime} . \mathrm{HO}^{\bullet}+\mathrm{H}_{2} \stackrel{k_{3^{\prime}}}{\longrightarrow} \mathrm{H}_{2} \mathrm{O}+\mathrm{H}^{\bullet}$,

$\Delta H^{\circ}{ }_{298}=-62.8 \pm 1.2$.

Inhibition

4. $\mathrm{HO}_{2}^{\bullet}+\mathrm{O}_{2} \stackrel{k_{4}}{\longrightarrow} \mathrm{HO}_{4}^{\bullet}$,

$\Delta H_{298}^{\circ}=110.0 \pm 15.4$.

Chain termination

5. $2 \mathrm{H}^{\bullet}(+\mathrm{M}) \stackrel{2 k_{5}}{\longrightarrow} \mathrm{H}_{2}(+\mathrm{M}), \quad \Delta H^{\circ}{ }_{298}=-436.0 \pm 0.0$;

6. $\mathrm{H}^{\cdot}+\mathrm{HO}_{4}^{\bullet} \stackrel{k_{6}}{\longrightarrow} \mathrm{H}_{2} \mathrm{O}_{2}+\mathrm{O}_{2}, \quad \Delta H_{298}^{\circ}=-476.6 \pm 13.7$

(or: $\mathrm{H}_{2} \mathrm{O}+\mathrm{O}_{3}, \quad \Delta H_{298}^{\circ}=-439.3 \pm 15.4$,

$\left.\mathrm{H}_{2}+2 \mathrm{O}_{2}\right), \Delta H_{298}^{\circ}=-340.6 \pm 13.7$;

7. $2 \mathrm{HO}_{4}^{\bullet} \stackrel{2 k_{7}}{\longrightarrow} \mathrm{H}_{2} \mathrm{O}_{2}+2 \mathrm{O}_{3}, \quad \Delta H_{298}^{\circ}=-95.0 \pm 30.8$.

The hydroperoxyl free radical $\mathrm{HO}_{2}^{\bullet}$ [46-50] resulting from reaction 2 possesses an increased energy due to the energy released the conversion of the $\mathrm{O}=\mathrm{O}$ multiple bond into the $\mathrm{HO}-\mathrm{O}^{*}$ ordinary bond. Therefore, before its possible decomposition, it can interact with a hydrogen or oxygen molecule as the third body via parallel (competing) reactions 3 and 4, respectively. The hydroxyl radical $\mathrm{HO}^{\circ}$ that appears and disappears in consecutive parallel reactions 3 (first variant) and $3^{\prime}$ possesses additional energy owing to the exothermicity of the first variant of reaction 3 , whose heat is distributed between the two products. As a consequence, this radical has a sufficiently high reactivity not to accumulate in the system during these reactions, whose rates are equal $\left(V_{3}=V_{3^{\prime}}\right)$ under

$\mathrm{HO}_{4}^{\circ}$ (the latter without the possible intramolecular hydrogen bond taken into account), $\mathrm{O}_{3}, \mathrm{H}_{2} \mathrm{O}$ [6], $\mathrm{H}_{2} \mathrm{O}_{2}$, and $\mathrm{H}_{2} \mathrm{O}_{4}$ is $218.0 \pm 0.0,39.0 \pm 1.2,12.6 \pm 1.7,122.6 \pm 13.7$, $143.1 \pm 1.7,-241.8 \pm 0.0,-136.0 \pm 0$, and $-26.0 \pm 9 \mathrm{~kJ}$ $\mathrm{mol}^{-1}$, respectively. Calculations for the $\mathrm{HO}_{4}^{\cdot}$ radical with a helical structure were carried out using the G2(MP2) method [39]. The stabilization energies of $\mathrm{HO}_{2}^{*}, \mathrm{HO}_{4}^{-}$, and $\mathrm{HO}_{3}^{\circ}$ were calculated in the same work to be $64.5 \pm$ $0.1,69.5 \pm 0.8$, and $88.5 \pm 0.8 \mathrm{~kJ} \mathrm{~mol}^{-1}$, respectively. The types of the $\mathrm{O}_{4}$ molecular dimers, their IR spectra, and higher oxygen oligomers were reported [40, 41]. The structure and IR spectrum of the hypothetical cyclotetraoxygen molecule $\mathrm{O}_{4}$, a species with a high energy density, were calculated by the CCSD method, and its enthalpy of formation was estimated [42]. The photochemical properties of $\mathrm{O}_{4}$ and the van der Waals nature of the $\mathrm{O}_{2}-\mathrm{O}_{2}$ bond were investigated [43, 44]. The most stable geometry of the dimer is two $\mathrm{O}_{2}$ molecules parallel to one another. The $\mathrm{O}_{4}$ molecule was identified by NR mass spectrometry [45]. quasi-steady-state conditions, according to the above scheme. Parallel reactions 3 (second, parenthesized variant) and $3^{\prime}$ regenerate hydrogen atoms. It is assumed $[27,28]$ that the hydrotetraoxyl radical $\mathrm{HO}_{4}^{*}$ (first reported in [51-53]) resulting from endothermic reaction 4 , which is responsible for the peak in the experimental rate curve (Fig. 2, curve 3), is closed into a five-membered

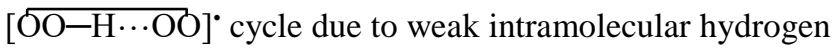
bonding $[25,54]$. This structure imparts additional stability to this radical and makes it least reactive.

The $\mathrm{HO}_{4}^{*}$ radical was discovered by Staehelin et al. [55] in a pulsed radiolysis study of ozone degradation in water; its UV spectrum with an absorption maximum at $260 \mathrm{~nm}$ $\left(\varepsilon\left(\mathrm{HO}_{4}^{*}\right)_{280 \mathrm{~nm}}=320 \pm 15 \mathrm{~m}^{2} \mathrm{~mol}^{-1}\right)$ was reported. The spectrum of the $\mathrm{HO}_{4}^{*}$ radical is similar to that of ozone, but the molar absorption coefficient $\varepsilon\left(\mathrm{HO}_{4}^{*}\right)_{\lambda_{\max }}$ of the former is almost two times larger [55]. The assumption about the cyclic structure of the $\mathrm{HO}_{4}^{\circ}$ radical can stem from the fact that its mean lifetime in water at $294 \mathrm{~K}$, which is $(3.6 \pm 0.4) \times 10^{-5} \mathrm{~s}$ (as estimated [37] from the value of $1 / k$ for the monomolecular decay reaction $\mathrm{HO}_{4}^{-} \stackrel{k}{\longrightarrow} \mathrm{HO}_{2}^{*}+\mathrm{O}_{2}$ [55]), is 3.9 times longer than that of the linear $\mathrm{HO}_{3}^{-}$radical $[39,56]$ estimated in the same way [37] for the same conditions [57], $(9.1 \pm 0.9) \times$ $10^{-6} \mathrm{~s}$.

MP2/6-311++G** calculations using the Gaussian-98 program confirmed that the cyclic structure of $\mathrm{HO}_{4}^{\cdot}$ [58] is energetically more favorable than the helical structure [39] (the difference in energy is 4.8-7.3 $\mathrm{kJ} \mathrm{mol}^{-1}$, depending on the computational method and the basis set). ${ }^{9}$ For example, with the MP2(full)/6-31G(d) method, the difference between the full energies of the cyclic and acyclic $\mathrm{HO}_{4}^{*}$ conformers with their zero-point energies (ZPE) values taken into account (which reduces the energy difference by $1.1 \mathrm{~kJ} \mathrm{~mol}^{-1}$ ) is $-5.1 \mathrm{~kJ} \mathrm{~mol}^{-1}$ and the entropy of the acyclic-to-cyclic $\mathrm{HO}_{4}^{\circ}$ transition is $\Delta S_{298}^{\circ}=-1.6$ $\mathrm{kJ} \mathrm{mol}^{-1} \mathrm{~K}^{-1}$. Therefore, under standard conditions, $\mathrm{HO}_{4}^{\cdot}$ can exist in both forms, but the cyclic structure is obviously dominant $\left(87 \%, K_{e q}=6.5\right)$ [58].

${ }^{9}$ There were calculations for the two conformers (cis and trans) of the $\mathrm{HO}_{4}^{\circ}$ radical [86] using large scale $a b$ initio methods and density functional techniques with extended basis sets. Both conformers have a nearly planar geometry with respect to the four oxygen atoms and present an unusually long central $\mathrm{O}-\mathrm{O}$ bond. The most stable conformer of $\mathrm{HO}_{4}^{-}$radical is the cis one, which is computed to be endothermic with respect to $\mathrm{HO}_{2}^{*}\left(X^{2} A^{\prime \prime}\right)+$ $\mathrm{O}_{2}\left(X^{3} \Sigma_{g}^{-}\right)$at $0 \mathrm{~K}$. 
Reaction 4 and, to a much lesser degree, reaction 6 inhibit the chain process, because they lead to inefficient consumption of its main participants $-\mathrm{HO}_{2}^{*}$ and $\mathrm{H}^{*}$.

The hydrogen molecule that results from reaction 5 in the gas bulk possesses an excess energy, and, to acquire stability within the approximation used in this work, it should have time for deactivation via collision with a particle M capable of accepting the excess energy [60]. To simplify the form of the kinetic equations, it was assumed that the rate of the bimolecular deactivation of the molecule substantially exceeds the rate of its monomolecular decomposition, which is the reverse of reaction 5 [6].

Reactions 6 and 7 (taking into account the principle of detailed balance for the various pathways) regenerate hydrogen and oxygen (in the form of $\mathrm{O}_{2}\left(X^{3} \Sigma_{g}^{-}\right)$

molecules, including the singlet states with $\Delta H_{f 298}^{\circ}\left(\mathrm{O}_{2}\right.$, $\left.a^{1} \Delta_{g}\right)=94.3 \mathrm{~kJ} \mathrm{~mol}^{-1}[20,41]$ and $\Delta H_{f 298}^{\circ}\left(\mathrm{O}_{2}, b^{1} \Sigma_{g}^{+}\right)=$ $161.4 \mathrm{~kJ} \mathrm{~mol}^{-1}$ [41], which are deactivated by collisions, and in the form of $\mathrm{O}_{3}$ ) and yield hydrogen peroxide or water via a nonchain mechanism, presumably through the intermediate formation of the unstable hydrogen tetraoxide molecule $\mathrm{H}_{2} \mathrm{O}_{4}[61,62] .{ }^{10}$ Ozone does not interact with molecular hydrogen. At moderate temperatures, it decomposes fairly slowly, particularly in the presence of $\mathrm{O}_{2}\left(X^{3} \Sigma_{g}^{-}\right)$[41]. The reaction of ozone with $\mathrm{H}^{\bullet}$ atoms, which is not impossible, results in their replacement with $\mathrm{HO}^{*}$ radicals. The relative contributions from reactions 6 and 7 to the process kinetics can be roughly estimated from the corresponding enthalpy increments (Scheme 2).

When there is no excess hydrogen in the hydrogen-oxygen system and the homomolecular dimer $\mathrm{O}_{4}[42-45,63,64]$, which exists at low concentrations (depending on the pressure and temperature) in equilibrium with $\mathrm{O}_{2}$ [41], can directly capture the $\mathrm{H}^{\cdot}$ atom to yield the heteronuclear cluster $\mathrm{HO}_{4}^{-},{ }^{11}$ which is more stable than $\mathrm{O}_{4}$ [41] and cannot abstract a hydrogen atom from the hydrogen molecule, nonchain hydrogen oxidation will occur to give molecular oxidation products via the disproportionation of free radicals.

The low-reactive hydrotetraoxyl radical $\mathrm{HO}_{4}^{\circ}$ [55], which presumably has a high energy density [42], may be an intermediate in the efficient absorption and conversion of biologically hazardous UV radiation energy the Earth

${ }^{10}$ The planar, six-atom, cyclic, hydrogen-bonded dimer $\left(\mathrm{HO}_{2}^{\circ}\right)_{2}$ was calculated using quantum chemical methods (B3LYP density functional theory) [88]. The hydrogen bond energy is 47.7 and $49.4 \mathrm{~kJ} \mathrm{~mol}^{-1}$ at $298 \mathrm{~K}$ for the triplet and singlet states of the dimer, respectively.

${ }^{11}$ It is impossible to make a sharp distinction between the two-step bimolecular interaction of three species via the equilibrium formation of the labile intermediate $\mathrm{O}_{4}$ and the elementary trimolecular reaction $\mathrm{O}_{2}+\mathrm{O}_{2}+\mathrm{H}^{\cdot} \rightarrow \mathrm{HO}_{4}^{\cdot}$. upper atmosphere. The potential energy surface for the atmospheric reaction $\mathrm{HO}^{-}+\mathrm{O}_{3}$, in which the adduct $\mathrm{HO}_{4}^{-}\left({ }^{2} A\right)$ was considered as an intermediate, was calculated by the DMBE method [65]. From this standpoint, the following reactions are possible in the upper troposphere, as well as in the lower and middle stratosphere, where most of the ozone layer is situated (altitude of $16-30 \mathrm{~km}$, temperature of $217-227 \mathrm{~K}$, pressure of $1.0 \times 10^{4}-1.2 \times 10^{3} \mathrm{~Pa}[66]$; the corresponding $\Delta H_{298}^{\circ}$ reaction values are given in $\mathrm{kJ} \mathrm{mol}^{-1}[20]$ ):

8. $\mathrm{H}_{2} \mathrm{O}$ (vapor) $+h v \rightarrow \mathrm{H}^{\bullet}+\mathrm{HO}^{\bullet} \quad[66]$;

9. $\mathrm{HO}^{\bullet}+\mathrm{O}_{3} \rightarrow \mathrm{HO}_{4}^{\bullet}[53,55,65], \quad \Delta H_{298}^{\mathrm{o}}=-59.5$;

10. $\mathrm{HO}_{4}^{\cdot} \rightarrow \mathrm{HO}_{2}^{\cdot}+\mathrm{O}_{2}\left(X^{3} \Sigma_{g}^{-}\right)[53,55,65], \Delta H_{298}^{\mathrm{o}}=-110.0$

$$
\text { (or } \mathrm{HO}_{2}^{\cdot}+\mathrm{O}_{2}\left(a^{1} \Delta_{g}\right), \quad \Delta H_{298}^{\mathrm{o}}=-15.7 \text {. }
$$

The $\mathrm{HO}_{4}^{\cdot}$ radical can disappear via disproportionation with a molecule, free radical, or atom in addition to dissociation. Note that emission from $\mathrm{O}_{2}\left(a^{1} \Delta_{g}\right)$ and $\mathrm{O}_{2}\left(b^{1} \Sigma_{g}^{+}\right)$is observed at altitudes of $30-80$ and $40-130$ $\mathrm{km}$, respectively [67].

Staehelin et al. [55] pointed out that, in natural systems in which the concentrations of intermediates are often very low, kinetic chains in chain reactions can be very long in the absence of scavengers since the rates of the chain termination reactions decrease with decreasing concentrations of the intermediates according to a quadratic law, whereas the rates of the chain propagation reactions decrease according to a linear law.

The kinetic description of the noncatalytic oxidation of hydrogen, including in an inert medium [60], in terms of the simplified scheme of free-radical nonbranched-chain reactions (Scheme 2), which considers only quadratic-law chain termination and ignores the surface effects [12], at moderate temperatures and pressures, in the absence of transitions to unsteady-state critical regimes, and at a substantial excess of the hydrogen concentration over the oxygen concentration was obtained by means of quasi-steady-state treatment, as in the previous studies on the kinetics of the branched-chain free-radical oxidation of hydrogen [47], even though the applicability of this method in the latter case under unsteady states conditions was insufficiently substantiated. The method was used with the following condition: ${ }^{12} k_{6}=\sqrt{2 k_{5} 2 k_{7}} \quad[1,8]$.

The equation $V_{3}\left(\mathrm{H}_{2} \mathrm{O}_{2} ; \mathrm{H}_{2} \mathrm{O}\right)=V_{3^{\prime}}\left(\mathrm{H}_{2} \mathrm{O}\right)$ for the rate of the chain formation of hydrogen peroxide in the reaction (3) and water in reactions 3 and $3^{\prime}$ with $V_{3,3^{\prime}}\left(\mathrm{H}_{2} \mathrm{O}\right)=2 V_{3}$ is

\footnotetext{
${ }^{12}$ For example, the ratio of the rate constants of the bimolecular disproportionation and dimerization of free radicals at room temperature is $k\left(\mathrm{HO}^{\circ}+\right.$ $\left.\mathrm{HO}_{2}{ }^{\circ}\right) /\left[2 k\left(2 \mathrm{HO}^{*}\right) 2 k\left(2 \mathrm{HO}_{2}{ }^{\circ}\right]^{0.5}=2.8\right.$ in the atmosphere [66] and $k\left(\mathrm{H}^{*}+\mathrm{HO}^{\circ}\right) /\left[2 k\left(2 \mathrm{H}^{*}\right) 2 k\left(2 \mathrm{HO}^{\circ}\right)\right]^{0.5}=1.5$ in water [4]. These values that are fairly close to unity.
} 
identical to Eq. $(1,1 \mathrm{a})$ with the corresponding analytical expression for $k_{2}$ provided that $\beta=0$ everywhere. The ratio of the rates of the competing reactions is $V_{3} / V_{4}=\alpha l / x$, and the chain length is $v=V_{3} / V_{1}$. The equations for the rates of nonchain formation of hydrogen peroxide and water via reactions 6 and 7 - quadratic-law chain termination - are identical to Eqs. (4) and (5) assuming that $\beta=0$. In these equations, $l$ and $x$ are the molar concentrations of hydrogen and oxygen $(l>x), l_{m}$ and $x_{m}$ are the respective concentrations at the maximum point of the function, $V_{1}$ is the rate of initiation (reaction 1 ), $\alpha=k_{3} / k_{4}$, the rate constant $k_{2}=\alpha l_{m} \sqrt{2 k_{5} V_{1}} / x_{m}^{2}$ is derived from the condition $\partial V_{3} / \partial x$ $=0$, and $2 k_{5}$ is the rate constant of reaction 5 (hydrogen atom recombination), which is considered as bimolecular within the given approximation.

The rate constant $2 k_{5}$ in the case of the pulsed radiolysis of ammonia-oxygen (+ argon) gaseous mixtures at a total pressure of $10^{5} \mathrm{~Pa}$ and a temperature of $349 \mathrm{~K}$ was calculated to be $1.6 \times 10^{8} \mathrm{dm}^{3} \mathrm{~mol}^{-1} \mathrm{~s}^{-1}$ [36] (a similar value of this constant for the gas phase was reported in an earlier publication [68]). Pagsberg et al. [36] found that the dependence of the yield of the intermediate $\mathrm{HO}^{\circ}$ on the oxygen concentration has a maximum close to $5 \times 10^{-4}$ mol dm${ }^{-3}$. In the computer simulation of the process, they considered the strongly exothermic reaction $\mathrm{HO}_{2}^{\cdot}+\mathrm{NH}_{3}$ $\rightarrow \mathrm{H}_{2} \mathrm{O}+{ }^{-} \mathrm{NHOH}$, which is similar to reaction 3 in Scheme 2 , whereas the competing reaction 4 was not taken into account.

The rate of the nonbranched-chain free-radical oxidation of hydrogen is a complex function of the rates of formation and disappearance of $\mathrm{H}^{\cdot}$ atoms and $\mathrm{HO}_{4}^{\cdot}$ radicals: $V_{1}+$ $V_{3,3^{\prime}}-V_{4}-V_{5}+V_{7}$. Unlike the dependences of the rates $V_{4}$ $\left(V_{4} \leq V_{1}\right), V_{5}$ and $V_{7}$, the dependences of the rates $V_{2}, V_{3,3}$, and $2 V_{6}$ on the oxygen concentration $x$ show a maximum.

Equation (1) with $\beta=0$ under the conditions $k_{2} x^{2} \gg(\alpha l+$ $x) \sqrt{2 k_{5} V_{1}}$ and $k_{2} x^{2} \ll(\alpha l+x) \sqrt{2 k_{5} V_{1}}, \alpha l \gg x$, corresponding to the descending and ascending branches of the curve with a maximum, can be transformed into simple equations which allow preliminary to estimate the parameters $\alpha$ and $k_{2}$ and express inversely (see Eq. (6)) and directly proportional functions of concentration $x$ :

$$
V_{3}=\sqrt{V_{1}} k_{2} x / \sqrt{2 k_{5}} .
$$

In the case of nonchain hydrogen oxidation via the above addition reaction $\left(\mathrm{H}^{\cdot}+\mathrm{O}_{4} \stackrel{k_{\text {add }}}{\longrightarrow} \mathrm{HO}_{4}^{*}\right)$, the formation rates of the molecular oxidation products in reactions 6 and 7 (Scheme 2, $k_{2}=k_{3}=k_{4}=0$ ) are defined by modified Eqs. (4) and (5) in which $\beta=0,(\alpha l+x)$ is replaced with 1 , and $k_{2}$ is replaced with $k_{a d d} K_{e q}\left(k_{a d d} K_{e q}\right.$ is the effective rate constant of $\mathrm{H}^{\bullet}$ addition to the $\mathrm{O}_{4}$ dimer, $K_{e q}=k / k^{\prime}$ is the equilibrium constant of the reversible reaction $2 \mathrm{O}_{2} \underset{k^{\prime}}{\stackrel{k}{\Leftrightarrow}}$ $\mathrm{O}_{4}$ with $\left.k^{\prime}>k_{\text {add }}\left[\mathrm{H}^{*}\right]\right)$. The formation rates of the stable products of nonchain oxidation $\left(k_{3}=0\right)$, provided that either reactions 2 and 4 or reaction 2 alone $\left(k_{4}=0\right)$ occurs (Scheme 2; in the latter case, reactions 6 and 7 involve the $\mathrm{HO}_{2}^{*}$ radical rather than $\mathrm{HO}_{4}^{*}$ ), are given by modified
Eqs. (4) and (5) with $\beta=0,(\alpha l+x)$ replaced with 1 , and $x^{2}$ replaced with $x$.

Note that, if in Scheme 2 chain initiation via reaction 1 is due to the interaction between molecular hydrogen and molecular oxygen yielding the hydroxyl radical $\mathrm{HO}^{*}$ instead of $\mathrm{H}^{\circ}$ atoms and if this radical reacts with an oxygen molecule (reaction 4) to form the hydrotrioxyl radical $\mathrm{HO}_{3}^{*}$ (which was obtained in the gas phase by neutralization reionization (NR) mass spectrometry [56] and has a lifetime of $>10^{-6} \mathrm{~s}$ at $298 \mathrm{~K}$ ) and chain termination takes place via reactions 5-7 involving the $\mathrm{HO}^{\circ}$ and $\mathrm{HO}_{3}^{*}$, radicals instead of $\mathrm{H}^{*}$ and $\mathrm{HO}_{4}^{*}$, respectively, the expressions for the water chain formation rates derived in the same way will appear as a rational function of the oxygen concentration $x$ without a maximum: $V_{3^{\prime}}\left(\mathrm{H}_{2} \mathrm{O}\right)=V_{1} k_{3} l /\left(k_{4} x+\sqrt{2 k_{5} V_{1}}\right)$.

Curve 2 in Fig. 1 describes, in terms of the overall equation $V_{3,7}=V_{1} x\left(\alpha l f_{m}+x^{3}\right) / f_{m}^{2}$ for the rates of reactions 3 and 7 (which was derived from Eqs. (1a) and (5), respectively, with $\beta=0$, Eq. (5) in the form [69] of $V_{7}=V_{1} x^{4} / f_{m}^{2} \quad$ (5a) in which $k_{2}$ is replaced with its analytical expression $\alpha l_{m} \sqrt{2 k_{5} V_{1}} / x_{m}^{2}$ derived from Eq. (1) with $\beta=0$ everywhere), the dependence of the hydrogen peroxide formation rate (minus the rate $V_{\mathrm{H}_{2} \mathrm{O}_{2}}=$ $5.19 \times 10^{-8} \mathrm{~mol} \mathrm{dm}{ }^{-3} \mathrm{~s}^{-1}$ of the primary formation of hydrogen peroxide after completion of the reactions in spurs) on the concentration of dissolved oxygen during the $\gamma$-radiolysis of water saturated with hydrogen (at the initial

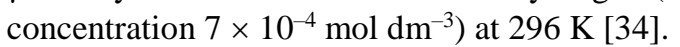

These data were calculated in the present work from the initial slopes of hydrogen peroxide buildup versus dose curves for a ${ }^{60} \mathrm{Co} \gamma$-radiation dose rate of $P=0.67 \mathrm{~Gy} \mathrm{~s}^{-1}$ and absorbed doses of $D \cong 22.5-304.0 \mathrm{~Gy}$. The following values of the primary radiation-chemical yield $G$ (species per $100 \mathrm{eV}$ of energy absorbed) for water $\gamma$-radiolysis products in the bulk of solution at $\mathrm{pH} \mathrm{4-9}$ and room temperature were used (taking into account that $V=G P$ and $V_{1}=G_{\mathrm{H}} P$ ): $G_{\mathrm{H}_{2} \mathrm{O}_{2}}=0.75$ and $G_{\mathrm{H}}=0.6$ (initiation yield) [4]; $V_{1}=4.15 \times 10^{-8} \mathrm{~mol} \mathrm{dm}^{-3} \mathrm{~s}^{-1} ; 2 k_{5}=2.0 \times 10^{10}$ $\mathrm{dm}^{3} \mathrm{~mol}^{-1} \mathrm{~s}^{-1}$ [4]. As can be seen from Fig. 1, the best description of the data with an increase in the oxygen concentration in water is attained when the rate $V_{7}$ of the formation of hydrogen peroxide via the nonchain mechanism in the chain termination reaction 7 (curve $1, \alpha$ $\left.=(8.5 \pm 2) \times 10^{-2}\right)$ is taken into account in addition to the rate $V_{3}$ of the chain formation of this product via the propagation reaction 3 (dashed curve $2, \alpha=0.11 \pm 0.026$ ). The rate constant of addition reaction 2 determined from $\alpha$ is substantially underestimated: $k_{2}=1.34 \times 10^{7}$ (vs $2.0 \times$ $10^{10}$ [4]) $\mathrm{dm}^{3} \mathrm{~mol}^{-1} \mathrm{~s}^{-1}$. The difference can be due to the fact that the radiation-chemical specifics of the process were not considered in the kinetic description of the experimental data. These include oxygen consumption via reactions that are not involved in the hydrogen oxidation Scheme 2 and reverse reactions resulting in the decomposition of hydrogen peroxide by intermediate 
products of water radiolysis $\left(\mathrm{e}_{\mathrm{aq}}^{-}, \mathrm{H}^{*}, \mathrm{HO}^{*}\right)$, with the major role played by the hydrated electron [4].

\section{CONCLUSIONS}

The above data concerning the competition kinetics of the nonbranched-chain addition of hydrocarbon free radicals and hydrogen atoms to the multiple bonds of the oxygen molecules make it possible to describe, using rate equations (1a) and (5a) obtained by quasi-steady-state treatment (the equation derivation is shown on p. 34), the peaking experimental dependences of the formation rates of molecular 1:1 adducts (in this case the $o-\mathrm{CH}_{3} \mathrm{C}_{6} \mathrm{H}_{4} \mathrm{CH}_{2} \mathrm{O}_{2} \mathrm{H}$ or $\mathrm{H}_{2} \mathrm{O}_{2}$ ) on the concentration of the oxygen over the entire range of its variation in binary systems (Fig. 1). In such reaction systems consisting of saturated and unsaturated components $[1,13-15,27,28$, $37,38,69-72]$, the unsaturated compound (in this case the $\mathrm{O}_{2}$ ) is both a reactant and an autoinhibitor, specifically, a source of low-reactive free radicals (in this case the $\mathrm{RO}_{4}^{*}$ or $\mathrm{HO}_{4}^{-}$radicals) shortening kinetic chains.

The progressive inhibition of the nonbranched-chain processes, which takes place as the concentration of the unsaturated compound is raised (after the maximum process rate is reached), can be an element of the self-regulation of the natural processes that returns them to the stable steady state.

Using mechanism of the nonbranched-chain free-radical hydrogen oxidation considered here, it has been demonstrated that, in the Earth's upper atmosphere, the decomposition of $\mathrm{O}_{3}$ in its reaction with the $\mathrm{HO}^{*}$ radical can occur via the addition of the latter to the ozone molecule, yielding the $\mathrm{HO}_{4}^{-}$radical, which is capable of efficiently absorbing UV radiation [55].

The kinetic equations obtained on the basis of the suggested reaction schemes involving pairs of competitive reactions at the chain evolution stage make it possible to directly determine the rate constant $k_{2}$ of the addition reaction 2 without using a separate labor-intensive method of competing reactions as often happens in such cases.

\section{REFERENCES}

[1] M. M. Silaev and L. T. Bugaenko, "Mathematical Simulation of the Kinetics of Radiation Induced Hydroxyalkylation of Aliphatic Saturated Alcohols", Radiation Physics and Chemistry, 1992, vol. 40, no. 1, pp. 1-10.

[2] I. V. Vereshchinskii and A. K. Pikaev, "Vvedenie v radiatsionnuyu khimiyu" ("Introduction to Radiation Chemistry”), Spitsyn, V.I., Editor, Akademiya Nauk SSSR, Moscow, 1963, p. 190.

[3] M. M. Silaev, "Applied Aspects of the $\gamma$-Radiolysis of $\mathrm{C}_{1}-\mathrm{C}_{4}$ Alcohols and Binary Mixtures on Their Basis", Khimiya Vysokikh Energii, Vol. 36, No. 2, 2002, pp. 97-101, English Translation in: High Energy Chemistry, 2002, vol. 36, no. 2, pp. 70-74.

[4] A. K. Pikaev, "Sovremennaya radiatsionnaya khimiya. Radioliz gazov i zhidkostei" ("Modern Radiation Chemistry: Radiolysis of Gases and Liquids"), Nauka, Moscow, 1986.

[5] N. M. Emanuel, E. T. Denisov, and Z. K. Maizus, "Tsepnye reaktsii okisleniya uglevodorodov v zhidkoi faze" ("Chain
Oxidation Reactions of Hydrocarbons in the Liquid Phase"), Nauka, Moscow, 1965.

[6] S. W. Benson, "Thermochemical Kinetics: Methods for the Estimation of Thermochemical Data and Rate Parameters", 2nd Edition, Wiley, New York, 1976.

[7] Ch. Walling, "Free Radicals in Solution", Wiley, New York, 1956.

[8] L. Bateman, "Olefin Oxidation”, Quarterly Reviews, 1954, vol. 8, no. 2, pp. 147-167.

[9] V. Ya. Shtern, "Mekhanizm okisleniya uglevodorodov v gazovoi faze (Mechanism of the Gas-Phase Oxidation of Hydrocarbons)", Akademiya Nauk SSSR, Moscow, 1960.

[10] H. L. J. Bäckström, "Der Kettenmechanismus bei der Autoxydation von Aldehyden", Zeitschrift für physikalische Chemie (B)", 1934, Bd. 25, № 1-2, Sn. 99-121.

[11] A. A. Aliev, and V. V. Saraeva, "Isomerization of Peroxy Radicals Resulting from the Radiation-Induced Oxidation of o-Xylene", Vestnik Moskovskogo Universiteta, Ser. 2: Khimiya, 1983, vol. 34, no. 4, pp. 371-374.

[12] E. J. Badin, "The Reaction between Atomic Hydrogen and Molecular Oxygen at Low Pressures. Surface Effects", Journal of the American Chemistry Society, 1948, vol. 70, no. 11, pp. 3651-3655.

[13] M. M. Silaev, "A New Competitive Kinetic Model of Radical Chain Oxidation: Oxygen as an Autoinhibitor", Biofizika, 2001, vol. 46, no. 2, pp. 203-209, English Translation in: Biophysics, 2001, vol. 46, no. 2, pp. 202-207.

[14] M. M. Silaev, "Simulation of the Initiated Addition of Hydrocarbon Free Radicals and Hydrogen Atoms to Oxygen via a Nonbranched Chain Mechanism", Teoreticheskie Osnovy Khimicheskoi Tekhnologii, 2007, vol. 41, no. 6, pp. 634-642, English Translation in: Theoretical Foundation of Chemical Engineering, 2007, vol. 41, no. 6, pp. 831-838.

[15] M. M. Silaev and L. T. Bugaenko, "Kinetics of the Addition of $\alpha$-Hydroxyalkyl Radicals to 2-Propen-1-ol and Formaldehyde", Kinetics and Katalysis, 1994, vol. 35, no. 4, pp. 509-513.

[16] L. V. Gurvich, G. V. Karachevtsev, V. N. Kondrat'ev, Yu. A. Lebedev, V. A. Medvedev, V. K. Potapov, and Yu. S. Khodeev, "Energii razryva khimicheskikh svyazei. Potentsialy ionizatsii i srodstvo k elektronu"("Bond Dissociation Energies, Ionization Potentials, and Electron Affinity"), V. N. Kondrat'ev, Editor, Nauka, Moscow, 1974.

[17] Yu. D. Orlov, Yu. A. Lebedev, and I. Sh. Saifullin, "Termokhimiya organicheskikh svobodnykh radikalov" ("Thermochemistry of Organic Free Radicals"), A. M. Kutepov, Editor., Nauka, Moscow, 2001.

[18] J. B. Pedley, R. D. Naylor, and S. P. Kirby, "Thermochemical Data of Organic Compounds", 2nd Edition, Chapman \& Hall, London, 1986.

[19] A. L. Buchachenko, "Kompleksy radikalov i molekulyarnogo kisloroda s organicheskimi molekulami" ("Complexes of Radicals and Dioxygen with Organic Molecules"), I. P. Beletskaya, Editor, Nauka, Moscow, 1984.

[20] J. S. Francisco and I. H. Williams, "The Thermochemistry of Polyoxides and Polyoxy Radicals", International Journal of Chemical Kinetics, 1988, vol. 20, no. 6, pp. 455-466.

[21] V. N. Kokorev, N. N. Vyshinskii, V. P. Maslennikov, I. A. Abronin, G. M. Zhidomirov, and Yu. A. Aleksandrov, "Electronic Structure and Chemical Reactions of Peroxides: I. MINDO/3 Calculation of the Geometry and Enthalpy of Formation of the Ground States of Organic and Organoelement Peroxides", Zhurnal Strukturnoi Khimii, 1981, vol. 22, no. 4, pp. 9-15.

[22] A. F. Dmitruk, V. V. Lobanov, and L. I. Kholoimova, "Role of Tetroxide Conformation in the Mechanism of Peroxy Radical Recombination", Teoreticheskaya i 
Eksperimental'naya Khimiya, 1986, vol. 22, no. 3, pp. 363-366.

[23] V. A. Belyakov, R. F. Vasil'ev, N. M. Ivanova, B. F. Minaev, O. V. Osyaeva, and G. F. Fedorova, "Electronic Model of the Excitation of Chemiluminescence in the Oxidation of Organic Compounds", Izvestiya Akademii Nauk SSSR, Ser.: Fizika, 1987, vol. 51, no. 3, pp. 540-547.

[24] P. Ase, W. Bock, and A. Snelson, "Alkylperoxy and Alkyl Radicals. 1. Infrared Spectra of $\mathrm{CH}_{3} \mathrm{O}_{2}$ and $\mathrm{CH}_{3} \mathrm{O}_{4} \mathrm{CH}_{3}$ and the Ultraviolet Photolysis of $\mathrm{CH}_{3} \mathrm{O}_{2}$ in Argon + Oxygen Matrices", The Journal of Physical Chemistry, 1986, vol. 90, no. 10 , pp. 2099-2109.

[25] G. C. Pimentel and A. L. McClellan, "The Hydrogen Bond", L. Pauling, Editor, Freeman, San Francisco, 1960, p. 200.

[26] G. A. Russell, "Deuterium-Isotope Effects in the Autooxidation of Aralkyl Hydrocarbons: Mechanism of the Interaction of Peroxy Radicals", Journal of the American Chemical Society, 1957, vol. 79, no. 14, pp. 3871-3877.

[27] M. M. Silaev, "The Competition Kinetics of Nonbranched Chain Processes of Free-Radical Addition to Double Bonds of Molecules with the Formation of 1:1 Adducts and the Inhibition by the Substrate", Oxidation Communication, 1999, vol. 22, no. 2, pp. 159-170.

[28] M. M. Silaev, "The Competition Kinetics of Radical-Chain Addition", Zhurnal Fizicheskoi Khimii, Vol. 73, No. 7, 1999, pp. 1180-1184, English Translation in: Russian Journal of Physical Chemistry, 1999, vol. 73, no. 7, pp. 1050-1054.

[29] A. P. Darmanyan, D. D. Gregory, Y. Guo, W. S. Jenks, L. Burel, D. Eloy, and P. Jardon, "Quenching of Singlet Oxygen by Oxygen- and Sulfur-Centered Radicals: Evidence for Energy Transfer to Peroxy Radicals in Solution", Journal of the American Chemistry Society, 1998, vol. 120, no. 2, pp. 396-403.

[30] J. R. Kanofsky, "Singlet Oxygen Production from the Reactions of Alkylperoxy Radicals. Evidence from 1268-nm Chemiluminescence", The Journal of Organic Chemistry, 1986, vol. 51, no. 17, pp. 3386-3388.

[31] N. N. Semenov, "Tsepnye reaktsii" ("Chain Reactions"), Goskhimtekhizdat, Leningrad, 1934, pp. 241, 203.

[32] M. Reznikovskii, Z. Tarasova, and B. Dogadkin, "Oxygen Solubility in Some Organic Liquids", Zhurnal Obshchei Khimii, 1950, vol. 20, no. 1, pp. 63-67.

[33] J. A. Howard and K. U. Ingold, "Absolute Rate Constants for Hydrocarbon Autooxidation. VI. Alkyl Aromatic and Olefinic Hydrocarbons", Canadian Journal of Chemistry, 1967, vol. 45, no. 8, pp. 793-802.

[34] N. F. Barr and A. O. Allen, "Hydrogen Atoms in the Radiolysis of Water", The Journal of Physical Chemistry, 1959, vol. 63, no. 6, pp. 928-931.

[35] H. A. Smith and A. Napravnik, "Photochemical Oxidation of Hydrogen", Journal of the American Chemistry Society, 1940, vol. 62, no. 1, pp. 385-393.

[36] P. B. Pagsberg, J. Eriksen, and H. C. Christensen, "Pulse Radiolysis of Gaseous Ammonia-Oxygen Mixtures", The Journal of Physical Chemistry, 1979, vol. 83, no. 5, pp. 582-590.

[37] M. M. Silaev, "Competitive Mechanism of the Non-branched Radical Chain Oxidation of Hydrogen Involvingthe Free Cyclohydrotetraoxyl Radical [OO $\left.\cdots \mathrm{H}^{\cdots} \mathrm{OO}\right]^{*}$, which Inhibits the Chain Process", "Khimiya Vysokikh Energii, 2003, vol. 37, no. 1, pp. 27-32, English Translation in: High Energy Chemistry, 2003, vol. 37, no. 1, pp. 24-28.

[38] M. M. Silaev, "Simulation of Initiated Nonbranched Chain Oxidation of Hydrogen: Oxygen as an Autoinhibitor", Khimiya Vysokich Energii, 2008, vol. 42, no. 2, pp. 124-129, English Translation in: High Energy Chemistry, 2008, vol. 42, no. 1 , pp. $95-100$.
[39] D. J. McKay and J. S. Wright, "How Long Can You Make an Oxygen Chain?", Journal of the American Chemistry Society, 1998, vol. 120, no. 5, pp. 1003-1013.

[40] N. P. Lipikhin, "Dimers, Clusters, and Cluster Ions of Oxygen in the Gas Phase", Uspekhi Khimii, 1975, vol. 44, no. 8, pp. 366-376.

[41] S. D. Razumovskii, "Kislorod - elementarnye formy i svoistva" ("Oxygen: Elementary Forms and Properties"), Khimiya, Moscow, 1979.

[42] K. M. Dunn, G. E. Scuceria, and H. F. Schaefer III, "The infrared spectrum of cyclotetraoxygen, $\mathrm{O}_{4}$ : A theoretical investigation employing the single and double excitation coupled cluster method", The Journal of Chemical Physics, 1990, vol. 92, no. 10, pp. 6077-6080.

[43] L. Brown and V. Vaida, "Photoreactivity of Oxygen Dimers in the Ultraviolet", The Journal of Physical Chemistry, 1996, vol. 100, no. 19, pp. 7849-7853.

[44] V. Aquilanti, D. Ascenzi, M. Bartolomei, D. Cappelletti, S. Cavalli, M. de Castro-Vitores, and F. Pirani, "Molecular Beam Scattering of Aligned Oxygen Molecules. The Nature of the Bond in the $\mathrm{O}_{2}-\mathrm{O}_{2}$ Dimer", Journal of the American Chemistry Society, 1999, vol. 121, no. 46, pp. 10794-1080.

[45] F. Cacace, G. de Petris, and A. Troiani, "Experimental Detection of Tetraoxygen", Angewandte Chemie, Internation Edition (in English), 2001, vol. 40, no. 21, pp. 4062-4065.

[46] H. S. Taylor, "Photosensitisation and the Mechanism of Chemical Reactions", Transactions of the Faraday Society, 1926, vol. 21, no. 63(3), pp. 560-568.

[47] A. B. Nalbandyan and V. V. Voevodskii, "Mekhanizm okisleniya i goreniya vodoroda" ("Mechanism of Hydrogen Oxidation and Combustion"), V. N. Kondrat'ev, Editor, Akad. Nauk SSSR, Moscow, 1949.

[48] S. N. Foner and R. L. Hudson, "Mass spectrometry of the $\mathrm{HO}_{2}$ free radical", The Journal of Chemical Physics, 1962, vol. 36 , no. 10, p. 2681.

[49] C. J. Hochanadel, J. A. Ghormley, and P. J. Ogren, "Absorption Spectrum and Reaction Kinetics of the $\mathrm{HO}_{2}$ Radical in the Gas Phase", The Journal of Chemical Physics, 1972, vol. 56, no. 9, pp. 4426-4432.

[50] P. D. Lightfoot, B. Veyret, and R. Lesclaux, "Flash Photolysis Study of the $\mathrm{CH}_{3} \mathrm{O}_{2}+\mathrm{HO}_{2}$ Reaction between 248 and 573 K", The Journal of Physical Chemistry, 1990, vol. 94, no. 2, pp. 708-714.

[51] P. Smith, "The $\mathrm{HO}_{3}$ and $\mathrm{HO}_{4}$ Free Radicals", Chemistry and Industry, 1954, no. 42, pp. 1299-1300.

[52] A. J. B. Robertson, "A Mass Spectral Search for $\mathrm{H}_{2} \mathrm{O}_{4}$ and $\mathrm{HO}_{4}$ in a Gaseous Mixture Containing $\mathrm{HO}_{2}$ and $\mathrm{O}_{2}$ ", Chemistry and Industry, 1954, no. 48, p. 1485.

[53] D. Bahnemann and E. J. Hart, "Rate Constants of the Reaction of the Hydrated Electron and Hydroxyl Radical with Ozone in Aqueous Solution", The Journal of Physical Chemistry, 1982, vol. 86, no. 2, pp. 252-255.

[54] "Vodorodnaya svyaz': Sbornik statei" ("The Hydrogen Bonding: Collection of Articles") N. D. Sokolov, Editor, Nauka, Moscow, 1981.

[55] J. Staehelin, R. E. Bühler, and J. Hoigné, "Ozone Decomposition in Water Studied by Pulse Radiolysis. 2. OH and $\mathrm{HO}_{4}$ as Chain Intermediates", The Journal of Physical Chemistry, 1984, vol. 88, no. 24, pp. 5999-6004.

[56] F. Cacace, G. de Petris, F. Pepi, and A. Troiani, "Experimental Detection of Hydrogen Trioxide", Science, 1999, vol. 285, no. 5424, pp. 81-82.

[57] R. F. Bühler, J. Staehelin, and J. Hoigné, "Ozone Decomposition in Water Studied by Pulse Radiolysis. 1. $\mathrm{HO}_{2} / \mathrm{O}_{2}{ }^{-}$and $\mathrm{HO}_{3} / \mathrm{O}_{3}{ }^{-}$as Intermediates", The Journal of Physical Chemistry, 1984, vol. 88, no. 12, pp. 2560-2564. 
[58] I. V. Trushkov, M. M. Silaev, and N. D. Chuvylkin, "Acyclic and Cyclic Forms of the Radicals $\mathrm{HO}_{4}^{\circ}, \mathrm{CH}_{3} \mathrm{O}_{4}^{\circ}$, and $\mathrm{C}_{2} \mathrm{H}_{5} \mathrm{O}_{4}^{-}$: $\mathrm{Ab}$ Initio Quantum Chemical Calculations", Izvestiya Akademii Nauk, Ser.: Khimiya, 2009, no. 3, pp. 479-482, English Translation in: Russian Chemical Bulletin, International Edition, 2009, vol. 58, no. 3, pp. 489-492.

[59] A. Mansergas, J. M. Anglada, S. Olivella, M. F. Ruiz-López, "On the Nature of the Unusually Long $\mathrm{OO}$ Bond in $\mathrm{HO}_{3}$ and $\mathrm{HO}_{4}$ Radicals", Phys. Chem. Chem. Phys., 2007, vol. 9, no. 44, pp. 5865-5873.

[60] W. Wong and D. D. Davis, “A Flash Photolysis Resonance Fluorescence Study of the Reactions of Atomic Hydrogen and Molecular Oxygen: $\mathrm{H}+\mathrm{O}_{2}+\mathrm{M} \rightarrow \mathrm{HO}_{2}+\mathrm{M}$ ", International Journal of Chemical Kinetics, 1974, vol. 6, no. 3, pp. 401-416.

[61] Yagodovskaya, T.V. and Nekrasov, L.I., Zhurnal Fizicheskoi Khimii, 1977, vol. 51, no. 10, pp. 2434-2445.

[62] X. Xu, R. P. Muller, and W. A. Goddard III, "The Gas Phase Reaction of Singlet Dioxygen with Water: A Water-Catalyzed Mechanism", Proceedings of the National Academy Sciences of the United States of America, 2002, vol. 99, no. 6, pp. 3376-3381.

[63] E. T. Seidl and H. F. Schaefer III, "Is There a Transition State for the Unimolecular Dissociation of Cyclotetraoxygen $\left(\mathrm{O}_{4}\right)$ ?", The Journal of Chemical Physics, 1992, vol. 96, no. 2, pp. $1176-1182$.
[66] "Atmosfera. Spravochnik" (“Atmosphere: A Handbook"), Gidrometeoizdat, Leningrad, 1991.

[67] H. Okabe, "Photochemistry of Small Molecules", Wiley, New York, 1978.

[68] A. W. Boyd, C. Willis, and O. A. Miller, "A Re-examination of the Yields in the High Dose Rate Radiolysis of Gaseous Ammonia", Canadian Journal of Chemistry, 1971, vol. 49, no. 13 , pp. 2283-2289.

[69] M. M. Silaev, "Competition Mechanism of Substrate-Inhibited Radical Chain Addition to Double Bond", Neftekhimiya, 2000, vol. 40, no. 1, pp. 33-40, English Translation in: Petroleum Chemistry, 2000, vol. 40, no. 1, pp. $29-35$.

[70] M. M. Silaev, "Competition Kinetics of Nonbranched Chain Processes of Free Radical Addition to the $\mathrm{C}=\mathrm{C}, \mathrm{C}=\mathrm{O}$, and $\mathrm{O}=\mathrm{O}$ Double Bonds of Molecules", Neftekhimiya, 2003, vol. 43, no. 4, pp. 302-307, English Translation in: Petroleum Chemistry, 2003, vol. 43, no. 4, pp. 258-273.

[71] M. M. Silaev, "Low-reactive Free Radicals Inhibiting Nonbranched Chain Processes of Addition", Biofizika, 2005, vol. 50, no. 4, pp. 585-600, English Translation in: Biophysics, 2005, vol. 50, no. 4, pp. 511-524.

[72] M. M. Silaev, "Kinetics of the Free-Radical Nonbranched-Chain Addition" // American Journal of Polymer Science and Technology, 2017, vol. 3, no. 3, pp. 29-49.
[64] R. Hernández-Lamoneda and A. Ramírez-Solís, "Reactivity and Electronic States of $\mathrm{O}_{4}$ along Minimum Energy Paths", The Journal of Chemical Physics, 2000, vol. 113, no. 10, pp. 4139-4145.

[65] A. J. C. Varandas and L. Zhang, "Test Studies on the Potential Energy Surface and Rate Constant for the $\mathrm{OH}+\mathrm{O}_{3}$ Atmospheric Reaction", Chemical Physics Letters, 2000, vol. 331, nos. 5-6, pp. 474-482. 